\title{
Lack of outcome research on New Zealand care and protection family group conference
}

\section{Teresia Kanyi}

Teresia Kanyi now works part time as a social worker for Baptcare Family Services in Moonee Ponds Melbourne, delivering the Integrated Family Services programme. She also works part time as a trainer and assesor in Certificate 111 Community Service for the Brotherhood of St Laurence in Fitzroy Melbourne. She can be contacted at: teresia422@gmail.com.

\section{Abstract}

Despite the popularity of the New Zealand care and protection family group conference (FGC) and its success in strengthening families, there is no evidence to show that the conference achieves its other desired outcome of protecting children from abuse and neglect. This evidence can only be obtained through evaluative research. For the FGC to maintain its credibility, the critical need for evaluative research in the New Zealand care and protection FGC needs to be addressed. Most of the other countries that have adopted the FGC have undertaken evaluative studies. New Zealand practitioners and researchers can draw from international evaluation studies and develop appropriate research designs and methodologies to evaluate New Zealand's care and protection FGC.

\section{Introduction}

Does the FGC provide safety and well-being for children? This is a key question in the current care and protection work. The question is particularly important in this era of evidence-based practice. Smith (2001) points out that social workers have a responsibility to demonstrate evidence-based practice in their practice and research.

In this paper, I aim to highlight the lack of outcome research on the New Zealand care and protection FGC. I will explore the process of the FGC, examine New Zealand and international research on the care and protection FGC and provide a discussion about the lack of outcome research in New Zealand. Furthermore, I will provide a discussion of the care and protection FGC desired outcomes and the difficulties associated with evaluation of social intervention.

\section{New Zealand family group conference}

The New Zealand FGC is a statutory decision-making body under section 28 of the Children, Young Persons, and Their Families Act 1989 (CYP\&F Act) (Hassall, 1996). The FGC is divided into youth justice FGC and care and protection FGC. This paper will focus on the care and protection FGC. 
The care and protection FGC aims at addressing the well-being of children by addressing their care and protection concerns, and strengthening their families so that they can provide them with long-term safety and well-being (Burford \& Pennell, 2004; Hassall, 1996). The key role of the FGC is to involve families in the decision-making process about their children through participation and empowerment. The FGC focuses on the children's needs and acknowledges the ability of the families/ whanau to adequately meet their children's needs and hence provide safety and well-being for their children (Hudson, Morris, Maxwell \& Galaway, 1996; Nash \& Munford, 1994). It is envisaged that in cases of care and protection concerns, the FGC will address these concerns by producing plans that can provide long-term safety and well-being for children, thereby providing stability for children and enhancing the family's cohesion (Burford \& Pennell, 2004). In care and protection, the FGC desired outcomes can be summarised as strengthening families and protecting children from abuse and neglect by providing them with safety and well-being.

Although the FGC started in New Zealand, it has spread to other countries that have also seen the need to involve families in the child welfare decision-making process (Burford \& Pennell, 2004). The USA, Australia, Britain, Canada, Sweden, Norway and Denmark are some of the countries that have adopted the FGC model. Sharing the responsibility of providing safety and well-being for children between the State and the family through the FGC is becoming an attractive form of intervention in this era of scarce resources and hence, more countries are adopting the FGC model in child welfare (Burford \& Pennell, 2004). At least 17 countries are using the FGC (Nixon, Burford, Quinn \& Edelbaum, 2005). It is important and timely to examine whether the popularity of the FGC is related to good outcomes for children.

\section{The care and protection FGC process}

The care and protection FGC is convened or reconvened by a care and protection coordinator, following a referral by a protective service, police or any other person holding care and protection concerns about a child (Connolly \& McKenzie, 1999). The venue of the FGC can either be formal or informal. The care and protection coordinator in consultation with the whanau/family decides the venue and also decides who participates and attends the conference.

Connolly (2004) asserts that, when the FGC was introduced in New Zealand following enactment of the CYP\&F Act, there was more emphasis on family involvement and less professional involvement. Section 23 of the CYP\&F Act requires that all available information required in making a decision is made available to the family. This requires the involvement of professionals in the conference. Such professionals have neither decision-making power nor are they entitled to remain in the meeting during the deliberation phase. The child, the child's family and other people who have a psychological attachment to the child, such as support people and close friends, are entitled to attend the conference (Connolly, 2001).

The care and protection coordinator provides the conference with the information about the case at hand and invites other professionals to give information. All the professionals then leave the family members to decide in private if there are care and protection concerns and to formulate a care plan to address the concerns. If the FGC cannot resolve the concerns, the State takes over the role of addressing the raised concerns (Fraser \& Norton, 1996). 
The formulated implementation plan is recorded and a copy given to all participants. The FGC is obliged by the CYP\&F Act to review the decisions and plans made at the conference from time to time. The care and protection coordinator is required to ensure that such reviews are carried out after the conference. The review is meant to ensure the continuous safety and well-being of the child, and maintain credibility of the FGC (Robertson, 1996).

The care and protection coordinator has the responsibility to ensure a balance between the rights and responsibilities of the State, and those of the community and the child, and proceeds with the whanau/family group wishes while still adhering to the CYP\&F Act's principles (Fraser and Norton, 1996). This requirement has generated debate in practice as professionals shift from the child protection practice to the family support practice which informs the FGC. Connolly (2004) predicts that the FGC may become a professional driven practice over time. A professional driven practice will override the principles of participation and empowerment of the family / whanau which were deemed necessary for the provision of long-term safety and well-being for children.

The role of coordination entails a shift of power to the family in a balanced way so that children's safety and the principles of the FGC are not compromised (Fraser \& Norton, 1996). Maintaining this balance is crucial in providing safety and well-being for children. It is crucial to establish whether the effort to maintain the balance between the rights and responsibilities of the State and those of the wider community undermines the FGC's desired outcome of providing safety and well-being for children.

\section{Research on New Zealand FGC outcomes}

A search of literature has revealed minimal and outdated research on New Zealand care and protection FGC. Available research has mainly centred on the process of the conference. This research has indicated that in most cases the FGC results in an agreement, and a plan is developed (Connolly \& McKenzie, 1999; Gilling, Patterson \& Walker, 1995; Mason, 1992; Paterson and Harvey, 1991). Making a plan has been seen as success in the FGC even when the plans are not evaluated. It is important to note that unless carried out, a plan does not necessarily guarantee safety and well-being for children.

Paterson and Harvey's (1991) and Mason's (1992) research findings on the New Zealand FGC reported that most FGC reached an agreement and that most professionals were satisfied by the plans made by the family. These studies are outdated; the FGC has continued to evolve and hence new studies need to inform current practice.

A New Zealand study in 1995 on the family members' experience of the FGC found that the conference provided a positive experience for families by improving family relationships and by empowering them to provide long-term safety for their children (Gilling, Patterson \& Walker, 1995). Furthermore, Gilling, Patterson \& Walker (1995) found that most decisions were implemented and families were generally satisfied with the process of the FGC. However, the study notes that some families complained about a number of issues: a lack of resources for implementing the plans; a lack of support from social workers in implementing the plans; and a lack of follow-up on the progress or regress of the plans. Apart from shaping future practice, this study highlights the need for reviewing the plans. 
Gilling, Patterson \& Walker's 1995 research shows that the FGC has achieved one of its desired outcomes; namely, strengthening families and fostering partnership with families. Although this is a positive outcome for the FGC, it is debatable whether it provides positive outcomes for children. A critical question here is: does the satisfaction of family members and professionals guarantee good outcomes for children? There is a need for research evidence to demonstrate that family member satisfaction with the conference correlates with positive outcomes for children.

The most recent research on the New Zealand care and protection FGC is the research findings of a study of care and protection coordinators published in 2004. The findings of this research highlighted the importance of honesty in the FGC process and recognised the power differentials within families and between professionals in the FGC process (Connolly 2004). Like the previous studies, this study's findings will help improve the process of the conference but it does not address the critical research gap of evaluative research in the New Zealand care and protection FGC.

New Zealand research has concluded that families have been strengthened and more children have remained in kinship placements than was the situation previously (Connolly, 2004; Gilling et al., 1995). It is also true that the FGC has helped in re-knitting family connections and creating a sense of pride for children and their families (Burford \& Pennell 2004; Hassall, 1996). Nevertheless, it is notable that even though the FGC plans are implemented, they are not always reviewed. Connolly and McKenzie (1999) states that too much emphasis has been put on decision-making with little or no emphasis on the review and follow-up phase of the FGC. For the Child Protection Family Group Conference to achieve its desired outcome of providing safety and well-being for children, review and evaluation of the process and outcomes must be undertaken.

\section{International research}

A critical analysis of whether the New Zealand FGC has achieved its desired outcomes has emphasised the need for evaluative research. An examination of international research undertaken on FGC outcomes may provide an insight on how to approach New Zealand's care and protection FGC evaluative research gap.

Velen and Devine (2005) carried out a FGC follow-up study in Arizona, evaluating the impact of family group decision-making on children with the greatest permanency needs. They concluded that, all in all, the FGC created a supportive relationship between children and their relatives through enhanced family connections as the family participated in the FGC process. This research shows that the FGC enhances children's well-being because good family connections and good sense of belonging is likely to lead to better outcomes for children. New Zealand needs to engage in such evaluative studies to maintain credibility and efficacy of the FGC in New Zealand care and protection work.

Pennell and Burford (1997) investigated the long-term outcomes of FGCs in Newfoundland and Labrador and compared their outcomes with those of traditional child protection interventions. Their findings indicated that children who had a FGC as opposed to a traditional child protection intervention were less likely to experience continued family violence due to enhanced family unity and decreased family vio- 
lence. They also found that keeping children free from family violence improved their quality of life. This study suggests that the FGC may provide children with safety and well-being. However, the study was carried out on a relatively small number of cases and with a non-random sample. Due to the nature of the research design and methodology of this study, applicability of the findings on a national and international level is questionable; furthermore, generalisation of the findings may be limited. Nonetheless, it is more beneficial to have a study with limitations than have none. At least the study gives an insight into the success of the FGC and highlights areas of improvement in the research design and methodology.

An evaluation study with 70 FGCs in Washington State invited families who had been in the welfare system for over 90 days to participate in the FGC decision-making process. The study analysed the FGC plans and the analysis provided information on immediate outcomes. The study also analysed the database of outcomes entered by the FGC facilitators. The database analysis provided information on the long-term impact on the children's well-being. The study concluded that generally, the FGC provided both immediate safety for children at risk and long-term stability and well-being for children (Gunderson, Cahn \& Wirth, 2003). This study recommended areas for improvements to its research design and methodology. The study recommended that a template of key outcomes and descriptive variables be created and used in different offices across Washington State to allow the use of a large, diverse sample in future evaluations. A further recommendation was that qualitative data is collected from social workers and families and used for future evaluations. This study provides important information on research design and methodology that could be used to evaluate New Zealand care and protection FGC.

Marsh and Crow (1997) examined the information of children's registration in the FGC, incidences of re-abuse after the FGC and sought professionals' views on whether the FGC had protected children from abuse in the UK. Their findings indicated that cases of re-abuse and re-registration were reduced and most professionals felt that the FGC protected children from abuse. Lupton and Stevens (1997) examined the family case history of children who had gone through the FGC for a period of 18 months after the FGC in the U.K. They found that most families were satisfied with the success of the FGC's plan in addressing the care and protection concerns.

Pennell and Burford (2000) evaluated interviews and progress reports of families experiencing domestic violence in Newfoundland and Labrador. They found that compared with other planning approaches, the FGC contributed to a reduction in cases of child abuse and maltreatment. Despite their methodological and research design shortcomings and the difficulty of linking a social work outcome with a single intervention, these studies provide evidence that the FGC has contributed to safety and well-being for children. Such evidence is required in New Zealand's care and protection work.

\section{The care and protection FGC desired outcomes}

As previously discussed, the FGC desired outcomes in care and protection work is strengthening families and protecting children from abuse and neglect. One of the achieved desired outcomes of the New Zealand FGC that has been highlighted by literature is the capacity 
of the conference to promote partnership and participation for families. Lupton and Nixon (1999) draw attention to the prescriptiveness of the CYP\&F Act that mandates the FGC to involve the family in the decision-making process in care and protection work. The fact that the FGC is a legal entity serves to enhance the family's participation in decision-making as professionals have to adhere to the principles of the Act in practice.

Lupton and Nixon (1999) have argued that the quality of the process of the FGC determines the outcomes. If families are strengthened, through good facilitation and management of the conference, they are likely to be in a better position to provide safety and well-being for their children. Connolly (2001) suggests that giving the family an upper hand in decision-making in the FGC is an investment in positive outcomes for the children. Connolly and McKenzie (1999) assert that harnessing the strength of families by empowering them to participate in FGC decision-making is the first step in the endeavour to provide safety for children. It is notable that even though strengthening family in itself is a desired outcome of the FGC, it is also a prerequisite of achieving the other desired outcome of protecting children from abuse and neglect. Stable and united families are likely to provide a stable home for a child. Stability for children is an important component of their well-being

Review of available research has revealed that generally families feel supported and strengthened while undergoing the process of the FGC and after the process. It is evident that the FGC desired outcome of strengthening families has been studied in New Zealand, some success has been reported and, more importantly, suggestions for further improvements of the process have been offered. Nonetheless, empirical evidence is required to ascertain that the conference has achieved its other desired outcome of providing safety and wellbeing for children by protecting them from abuse and neglect.

\section{Lack of evaluation research in New Zealand care and protection FGC}

Unlike other countries that have adopted the FGC process, New Zealand has not invested much on evaluative research (Connolly, 2006). Subsequently, it is difficult to prove by evidence-based practice that the FGC does provide safety and well-being for children by protecting them from abuse and neglect.

Hudson, Morris, Maxwell \& Galaway (1996) reviewed evidence on the New Zealand FGC and concluded that much of the research centred on the process and implementation of the FGC and emphasised the need for evaluative research. An official review of the CYP\&F Act highlighted the lack of the FGC's outcome research (Mason, 1992). Maxwell and Pakura (2006) state that New Zealand FGC has '....relatively little empirical evidence that can conclusively link specific aspects of the practice to outcomes' (p. 2). It is important that the FGC is evaluated so as to demonstrate its efficacy as a model of intervention. It is also important that the work of the conference is accountable to the children, families, funders and the public. Such accountability can be demonstrated by evidence-based practice which requires evaluation of the care and protection FGC.

Stevens (1999) argues that it is difficult to carry out evaluative research in care and protection work due to the different interests of the stakeholders involved. These stakeholders include: the family, the service funder, the service providers, policy makers and the children. These groups' interest in FGC may compete and the competition is further complicated 
by questions such as: who funds the research and who undertakes the research? Lack of evaluative research has created uncertainty on the viability of the FGC as a model of intervention in care and protection amongst stakeholders. This uncertainty is likely to contribute to lack of confidence in care and protection work, and to unwarranted blame and criticism directed to professionals by the public, the media and other stakeholders. Furthermore, care and protection work has received criticism in the recent past due to increased cases of child abuse (Connolly, 2004)

The complex nature of social work creates difficulties in evaluative research. Unlike natural science, social work outcomes cannot be explained simply as consequences of interventions or services provided (Stevens, 1999). Factors such as social environment, history of the people, prevailing economic and political ideology, oppressive structures, etc, make it difficult to apply the scientific theory of causality to evaluative research in the FGC. The fact that different stakeholders are likely to have different interpretations and descriptions of the situation and also because subjectivity is part and parcel of social work has contributed to lack of a defined criteria for measuring outcomes in social work. There is no preferred research method and design that would accurately show that the children have been provided with safety and well-being (Stevens, 1999). The Ministry of Social Development (2006) confirms that data has been collected on the process of the FGC but no evaluative research has been carried out due to lack of a valid outcome measurement criterion.

To overcome the difficulty associated with evaluation of social intervention using natural science methods discussed previously by Stevens (1999), Smith (2001) suggests that a postmodernist approach to research along with social workers taking an active role in research is the way forward. The author's experience in social work practice supports the view that social workers have a lot to offer in research. This could be from the information they gather through assessments and other social work processes. Such information can be recorded and used for evaluative research. There is a need for a pro-active search for a research design that is suitable for New Zealand care and protection FGC evaluative research.

\section{Conclusion}

The primary desired outcomes of the FGC are to provide safety and well-being for children and to strengthen families. These two outcomes are based on the original aim of the conference which is to protect children from abuse and neglect while still strengthening families. The two desired outcomes are closely related because a unified family is more able to provide safety for children than a fragmented one, and also because strengthening families will guarantee long-term safety and well-being for the child in need of care and protection and for other children in the family.

Although research in New Zealand shows that the FGC has contributed positively to family empowerment and participation in decision-making, further research is required on outcome. The growing need for evidence-based practice requires practitioners and researchers to engage in the care and protection FGC evaluation research so that they can demonstrate to the public and to the stakeholders that the FGC does provide safety and well-being for children. This research would not only improve practice but would also boost public confidence and consequently increase family/whanau and public support for the FGC. 
The criticism of New Zealand care and protection FGC stems from lack of evaluative research. There is need for empirical research on the success of the FGC as a model of intervention in New Zealand care and protection work. This will ensure continued safety and well-being for children and maintain the credibility of the conference. Nonetheless, the FGC as a model is still developing in practice. It is an innovative model of practice that is developing in an era that demands a sound professional practice, and evidence-based practice to match the demands for accountability and efficiency in today's social work practice.

\section{References}

Burford, G., \& Pennell, J. (2004). From the agency client to community based consumer: The family group conference as a consumer-led group in child welfare. In D. C. Garvin, M., L. Gutierrez \& J. M. Galinsky (Eds), Handbook of social work with groups (pp. 415-446). London: Guilford Press.

Connolly, M. (2001). New Zealand social work: Contexts and practice. Auckland: Oxford University Press.

Connolly, M. (2004). Child and family welfare: Statutory response to children at risk. Christchurch: Te Awatea Press.

Connolly, M. (2006). Fifteen years of family group conferencing: Coordinators talk about their experiences in Aotearoa New Zealand. British Journal of Social Work, 36, 523-540.

Connolly, M. \& McKenzie, M. (1999). Effective participatory practice: Family group conference in child protection. New York: Aldine De Gruyter.

Fraser, S., \& Norton, J. (1996). Family group conferencing in New Zealand child protection work. In J. Hudson, A. Morris, G. Maxwell, \& B. Galaway (Eds), Family group conference: Perspectives policy and practices (pp.37-48). NSW: Federation Press.

Gilling, M., Patterson, L., \& Walker, B. (1995). Family members' experiences of the care and protection family group conference process. Wellington: Social Policy Agency.

Gunderson, K., Cahn, K., \& Wirth, J. (2003). The Washington State long term outcome study. Protecting Children, $18,1 \& 2,42-47$.

Hassall, I. (1996). Origin and development of family group conference. In J. Hudson, A. Morris, G. Maxwell, \& B. Galaway (Eds), Family group conference: Perspectives policy and practices (pp.17-36). NSW: Federation Press.

Hudson, J., Morris, A., Maxwell, G., \& Galaway, B. (Eds). (1996). Family group conferences: Perspectives on policy and practice. NSW: Federation Press.

Lupton, C., \& Nixon, P. (1997). Empowering practice: A critical appraisal of the Family Group Conference approach. Bristol: The Policy Press.

Lupton, C., \& Stevens, M. (1997). Family outcomes: Following through on family group conference. Portsmouth: Social Services Information Unit, University of Portsmouth.

Marsh, P., \& Crow, G. (1997). Family group conferences in child welfare. Oxford: Blackwell.

Mason, K. (1992). Report of the ministerial review team to the Minister of Social Welfare. Wellington: Ministerial Review Team.

Maxwell, G., \& Pakura, S. (2006). The family group conference: Does it work for child protection? Retrieved from http: / / igps.victoria.ac.nz/ events / completedactivities/RJ\%20Mexico/CareProtFGC.pdf.

Ministry of Social Development (2006). Family group conferences. Retrieved from http: / www.cyf.govt.nz.

Munford, R., \& Nash, M. (1994). Social work in action. Palmerston North: Dunmore Press.

Nixon, P., Burford, G., Quinn, A., \& Edelbaum, J. (2005). A survey of international practices, policy E research on family group conferencing and related practices. Retrieved from: www.americanhumane.org.

Paterson, K., \& Harvey, M. (1991). An evaluation of the organisation and operation of care and protection family group conference. Wellington: Department of Social Welfare.

Payne, M. (1997). Modern social work theory (2nd ed.). Hampshire: Palgrave.

Pennell, J., \& Burford, G. (1997). Family group decision making project: Outcome summary report. Newfoundland, Canada: Memorial University.

Pennell, J., \& Burford, G. (2000). Family group decision making: Protecting children and women. Child Welfare, $79,2,131-158$.

Robertson, J. (1996). Research on family group conference in child welfare in New Zealand. In J. Hudson, A. Morris, G. Maxwell \& B. Galaway (Eds), Family group conference: Perspectives policy and practices (pp.49-64). NSW: Federation Press.

Smith, C. (2001). Research and the theory / practice interface. In M. Connolly (Ed), New Zealand social work: Contexts and practice (pp. 343-355). Auckland: Oxford University Press.

Stevens, M. (1999). Assessing outcomes in child welfare. In C. Lupton \& P. Nixon (Eds), Empowering practice: A critical appraisal of the family group conference approach. Bristol: Polity Press.

Turnell, A., \& Edwards, S. (1999). Signs of safety: A solution and safety oriented approach to child protection casework. New York: Norton.

Velen, M., \& Devine, L. (2005). Use of FGDM with children in care the longest: It's about time. Protecting Children, 19, 4, 25-35. 